
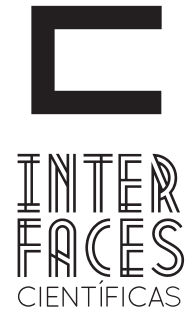

DIREITO

\title{
TRANSPORTE PÚBLLCO URBANO: CONDIÇ̃̃ES DOS TERMINAIS DE INTEGRAÇÃO NA REGIÃO METROPOLITANA DE ARACAJU/SE
}

\section{RESUMO}

A pesquisa teve por objetivo conhecer as condições do transporte público urbano dentro dos terminais de integração de ônibus na região metropolitana de Aracaju, assim como a visão dos seus usuários no que concerne à finalidade da utilização, e às condições de atendimento das necessidades da população, à qualidade geral desse serviço e à necessidade de mudanças. Conhecendo essa percepção, foi possível gerar o conhecimento necessário para a sugestão de alterações no atendimento ao público e à criação de ações e políticas públicas objetivando a promover o respeito aos direitos de cidadania, no âmbito dos transportes coletivos. 0 estudo, de base quali-quantitativa, foi realizado através de dados secundários e primários com levantamento de campo nos nove terminais de integração de Aracaju, permitindo concluir que as condições de atendimento desse serviço público são consideradas inadequadas pelos usuários do sistema.

\section{PALAVRAS-CHAVE}

Terminais de Integração de Ônibus. Aracaju. Políticas Públicas. 


\section{ABSTRACT}

The research aimed to know the conditions of urban public transport within the terminals of bus integration in the metropolitan area of Aracaju and vision of its users about the purpose of use, conditions of service of the population, the overall quality of service and need for change, fundamental knowledge for the suggestion of changes in customers service and creating actions and policies aimed at promoting respect for the rights of citizenship in the context of public transportation. The study, based on qualitative and quantitative approach, was conducted through secondary and primary data with field survey in the nine terminals integration of Aracaju, allowing to the conclusion that the system users consider the conditions of service of public service inappropriate.

\section{KEYWORDS}

Terminals Bus Integration. Aracaju. Public Policies.

\section{RESUMEN}

La investigación tuvo por objetivo conocer las condiciones del transporte público urbano dentro de los terminales de integración de autobuses en la región metropolitana de Aracaju, como también la visión de sus usuarios a respecto de la finalidad de su utilización y de las condiciones de atendimiento de las necesidades de la población, así como la calidad general de este servicio y la necesidad de cambios. Conociendo esa percepción, fue posible generar el conocimiento necesario para la sugerencia de cambios en el atendimiento al público y la creación de acciones y políticas públicas con el objetivo de promover el respeto a los derechos de ciudadanía, en el ámbito de los transportes colectivos. El estudio, de base cali-cantitativa, fue realizado a través de datos secundarios y primarios con levantamiento de campo en los nueve terminales de integración de Aracaju, permitiendo concluir que las condiciones de atendimiento de ese servicio público son consideradas inadecuadas por los usuarios del sistema.

\section{PALABRAS CLAVE}

Terminales de Integración de Autobuses. Aracaju. Políticas Públicas.

\section{CIDADANIA, CRESCIMENTO URBANO E TRANS- PORTE PÚBLICO}

A ideia de cidadania, embora tenha passado por diferentes conotações ao longo dos tempos e ainda não seja um conceito homogêneo nas várias partes do mundo, na maior parte dos países pressupõe o atendimento a direitos básicos dos seres humanos, como educação, saúde, transporte, moradia, trabalho, segurança, dentre outros, cabendo ao Estado a responsabilidade pela garantia desses direitos.

No Brasil esses direitos estão longe de ser garantidos, embora muitas sejam as ações no sentido de melhorar as condições de vida e garantir o acesso às condições fundamentais da cidadania, especialmente nos primeiros anos deste século, quando o avanço da tecnologia impulsiona o crescimento econômico que, por sua vez, estimula o crescimento urbano (ROSA, 2006).

Esse processo de crescimento urbano, que ocorre em nível planetário, se dá de forma bastante acelerada no Brasil, onde muitas metrópoles surgiram nas últimas décadas, exigindo boa capacidade de trans- 
porte tanto para a distribuição da produção quanto para o deslocamento de pessoas nas suas atividades cotidianas, principalmente vinculadas ao trabalho e ao estudo.

O crescimento urbano, acompanhado pelo aumento do dinamismo econômico, vem refletindo no rápido aumento da frota de veículos que circulam nas cidades, sem que a infraestrutura viária consiga acompanhar esse aumento do tráfego. Isso vem causando uma série de problemas, que refletem no aumento da poluição do ar e do tempo gasto em deslocamentos, no nível de estresse de motoristas, passageiros e pedestres, no crescimento do índice de acidentes de trânsito, na lotação de transportes coletivos e outros, que incidem diretamente na diminuição da qualidade de vida nas médias e grandes cidades (KOIZUMI; JORGE, 2007).

O trânsito é uma atividade fundamental para o deslocamento de pessoas, e sua importância vem crescendo acentuadamente face à complexidade da vida moderna, especialmente nas grandes cidades, onde os locais de residência, trabalho, lazer, serviços e outros, se encontram espacialmente distantes uns dos outros, exigindo o deslocamento entre as várias partes da cidade através de algum meio de transporte. Para as classes menos abastadas, esse deslocamento depende, essencialmente, dos transportes coletivos, sem o que a população não teria condições de acesso a esses diferentes espaços (GOMIDE, 2003).

0 aumento da complexidade urbana tem exigido que inúmeros instrumentos sejam usados para melhorar a qualidade do ambiente nas cidades, destacando-se aqueles relacionados à mobilidade urbana, com o intuito de conceder à população a melhoria no seu direito de ir e vir, o que reflete, de forma significativa, na sua qualidade de vida. Entendendo a importância da mobilidade urbana para o melhoramento da qualidade ambiental urbana e o desenvolvimento das cidades, foi aprovada em 3 de janeiro de 2012, pelo Governo Federal, a Lei $n^{0} 12.587$ que institui as diretrizes da Política Nacional de Mobilidade Urbana, objetivando a integração dos diferentes tipos de transporte e a melhoria da acessibilidade e mobilidade das pessoas e cargas no território dos municípios (BRASIL, 2012).

Porém, a promulgação de uma lei ou o estabelecimento de diretrizes políticas não são ações suficientes, pois é necessário que melhorias sejam implementadas, de fato, e a população alvo seja adequadamente informada e orientada para que as benfeitorias realizadas com a concretização política sejam mais bem utilizadas e preservadas (SAULE JR., 2006).

Novos instrumentos vêm sendo criados para complementar e integrar a gestão ambiental urbana, mas os resultados deixam muito a desejar, especialmente quando se referem às condições de deslocamento dentro da cidade com o uso de veículos particulares ou de transporte coletivo, quer devido à complexidade de adequação da malha viária, quer devido à falta de educação para o trânsito.

Ações educativas, que visam à conscientização da população sobre os cuidados com o ambiente construído, especialmente vias de circulação e educação para o trânsito, vêm sendo desenvolvidas de forma tímida e apresentando eficácia duvidosa, pois não são observadas mudanças comportamentais significativas. Esse quase fracasso das ações educativas deve ser analisado considerando-se as dificuldades na adequação do espaço urbano para permitir a apropriada ligação entre as várias partes da cidade, bem como a falta de respeito para com o usuário de transporte coletivo, que depende de sistemas mal planejados, com rotas e horários que não atendem a necessidade dos passageiros, de veículos com superlotação em horários de pico, equipamentos mal conservados, motoristas e cobradores pouco capacitados para atendimento ao público e outros problemas que causam estresse na população das médias e grandes cidades. 


\section{TERMINAIS DE INTEGRAÇÃO, E PERCEPÇÃO DOS USUÁRIOS EM ARACAJU}

Na capital do Estado de Sergipe, o transporte coletivo urbano se faz exclusivamente por sistema de ônibus, tendo como agravante a concessão de permissão para exploração de linhas sem qualquer tipo de licitação pública e, portanto, sem o estabelecimento da concorrência entre empresas quanto ao oferecimento de melhores condições ao usuário para o deslocamento dentro da cidade. Assim, a avaliação das condições desse serviço público essencial para o exercício das atividades cotidianas da população de Aracaju se constitui em ação importante para subsidiar decisões e políticas públicas que considerem o bem estar dos usuários do sistema de transporte coletivo urbano, direito intrínseco à cidadania.

O serviço de transporte público urbano de Aracaju e região metropolitana é feito através de um sistema integrado que permite ao passageiro mudar de ônibus sem que seja necessário pagar nova passagem. Assim, todas as partes da cidade estão ligadas às demais, através de ônibus urbano com o pagamento de uma só tarifa. Esse transbordo é feito em nove terminais de integração mantidos pelas empresas que operam o transporte coletivo em Aracaju. Os terminais são: Centro, Zona Oeste, Mercado, Campus Universitário, São Cristovão, Distrito Industrial, Zona Sul, Marcos Freire e Maracaju (SMTT, 2012).

Visando a conhecer o funcionamento e as condições dos terminais de integração, este estudo foi elaborado com dados primários e secundários, sendo estes últimos disponibilizados à consulta pública, como manuais, estatutos e normas, acervos/cadastros da Superintendência Municipal de Transporte e Trânsito de Aracaju e bibliotecas.

Os dados primários para o estudo foram levantados por observação direta e junto a usuários do sistema de transporte coletivo de Aracaju, através da aplicação de questionário específico para coleta de informações nos terminais de integração de Aracaju: Maracaju, Distrito Industrial de Aracaju (DIA), Zona Oeste, Centro, Zona Sul, Mercado, Campus (Universidade Federal de Sergipe), Rodoviária de São Cristóvão e Marcos Freire (Nossa senhora do Socorro), relatórios e estudos realizados sobre a temática.

A coleta de dados junto aos usuários buscou conhecer a sua percepção acerca das condições gerais do transporte coletivo urbano de Aracaju e sua região metropolitana, sendo aplicados 400 questionários nos nove terminais de integração de ônibus. A amostragem foi a que estava prontamente acessível, sendo critérios de inclusão: ser maior de 18 anos e usuário de transporte coletivo. Foram considerados critérios de exclusão: ser menor de 18 anos, aparentar estar alcoolizado e não compreender o escopo da pesquisa. 0 instrumento utilizado, o questionário, foi preenchido pelos entrevistadores de forma a evitar que analfabetos fossem excluídos da pesquisa ou que analfabetos funcionais não tivessem condições de responder as questões.

0 estudo permitiu observar que os terminais de integração estão bem distribuídos na malha urbana, recebendo diariamente um grande volume de pessoas, o que significa levar o benefício da integração de transporte por ônibus à população usuária desse tipo de transporte na capital do Estado. Mas, as condições de utilização dos terminais, da infraestrutura física e o disciplinamento do uso do espaço apresentam problemas para os usuários, especialmente aqueles mais vulneráveis à circulação em locais de alta densidade de pessoas, como idosos, deficientes físicos e crianças.

A percepção dos usuários do transporte coletivo urbano que participaram da amostra levantada por cada terminal de integração indicou o descontenta- 
mento generalizado para com as condições físicas dos terminais, como pode ser observado nos dados das tabelas seguintes. Observou-se que a grande maioria dos terminais se encontra com aspecto deteriorado, sendo que nenhum deles recebeu mais de $26 \%$ de aprovação das suas condições físicas, com avaliação "Bom", com destaque para os terminais da Zona Oeste, Marcos Freire e Maracaju, que obtiveram percentuais acima de $20 \%$ de avaliação positiva. Mas, se forem somados os percentuais de resposta "Bom" e "Regular", indicando relativa satisfação com as condições dos terminais, destacam-se cinco terminais: Maracaju, com 93,3\% de respostas apontando serem boas ou regulares as condições desse terminal, seguido do terminal de São Cristóvão (80,0\%), Zona Oeste $(69,4 \%)$ e Marcos Freire (62,5\%).

Tabela 1 - Avaliação das condições físicas dos terminais

\begin{tabular}{|l|c|c|c|}
\hline \multirow{2}{*}{ Terminais } & \multicolumn{3}{|c|}{ Avaliação do terminal que mais usa } \\
\cline { 2 - 4 } & Bom & Regular & Ruim \\
\hline Campus & 0,0 & 36,4 & 63,6 \\
\hline Centro & 6,8 & 42,4 & 50,8 \\
\hline Distrito Industrial & 3,3 & 38,3 & 58,3 \\
\hline Maracaju & 23,3 & 70,0 & 6,7 \\
\hline Marcos Freire & 25,0 & 37,5 & 37,5 \\
\hline Mercado & 3,3 & 43,3 & 53,3 \\
\hline São Cristóvão & 0,0 & 80,0 & 20,0 \\
\hline Zona Oeste & 28,6 & 40,8 & 30,6 \\
\hline Zona Sul & 0,0 & 32,5 & 67,5 \\
\hline \multicolumn{1}{|c|}{ Total } & $\mathbf{9 , 7}$ & $\mathbf{4 2 , 7}$ & $\mathbf{4 7 , 6}$ \\
\hline
\end{tabular}

Fonte: Pesquisa de campo (2011/2012)

Observando-se apenas o volume de respostas "Ruim", o terminal de integração pior avaliado foi o da Zona Sul, seguido do Campus Universitário, ambos com mais de $60 \%$ de respostas "Ruim", e o Distrito Industrial e o Centro, com mais de $50 \%$ de respostas negativas quanto à qualidade da infraestrutura em geral.

Analisando os aspectos da infraestrutura que foram avaliados individualmente em seleção de múltipla escolha pelos 400 pesquisados, observa-se que, dos 1.847 registros de aspectos negativos relacionados aos seis fatores listados no questionário, destaca-se a segurança, embora não haja grande diferença no volume das recla- mações sobre a infraestrutura dos terminais de integração (Tabela 2). O fator segurança foi apontado como problema por 355 pesquisados, representando 19,3\% dos aspectos negativos listados; os problemas na estrutura foram citados por 314 pesquisados, perfazendo $17,1 \%$ das queixas; a falta de conforto, apontada como problema por 303 pesquisados (16,5\% das queixas) foi seguida de problemas em banheiros com más condições de conservação e falta de higiene, citado por 299 pesquisados ( $16,3 \%$ das queixas); a falta de sistema adequado de informações foi apontada por 291 pesquisados $(15,9 \%$ das queixas) e falta de higiene e problemas de limpeza foi apontado por 273 pesquisados (14,9\%). 
Tabela 2 - Aspectos apontados como negativos do terminal de integração que o usuário mais utiliza - Percentual por terminal de integração

\begin{tabular}{|l|c|c|c|c|c|c|c|}
\hline \multicolumn{1}{|c|}{ Terminal } & Informação & Conforto & Higiene & Banheiro & Estrutura & Segurança & Total \\
\hline Campus & 19,0 & 19,0 & 4,9 & 19,0 & 19,0 & 19,0 & $\mathbf{1 0 0 , 0}$ \\
\hline Centro & 16,1 & 16,1 & 16,6 & 16,1 & 17,5 & 17,7 & $\mathbf{1 0 0 , 0}$ \\
\hline Distrito Industrial & 16,2 & 16,2 & 17,1 & 15,6 & 17,1 & 17,8 & $\mathbf{1 0 0 , 0}$ \\
\hline Maracaju & 10,8 & 15,3 & 17,1 & 12,6 & 18,0 & 26,1 & $\mathbf{1 0 0 , 0}$ \\
\hline Mercado & 13,8 & 14,9 & 16,1 & 18,4 & 14,9 & 21,8 & $\mathbf{1 0 0 , 0}$ \\
\hline S. Cristóvão & 15,4 & 15,4 & 19,2 & 15,4 & 15,4 & 19,2 & $\mathbf{1 0 0 , 0}$ \\
\hline Zona Oeste & 13,3 & 14,3 & 17,1 & 14,8 & 17,1 & 23,3 & $\mathbf{1 0 0 , 0}$ \\
\hline Zona Sul & 15,3 & 15,8 & 17,5 & 15,8 & 20,2 & 15,3 & $\mathbf{1 0 0 , 0}$ \\
\hline Marcos Freire & 14,9 & 21,3 & 14,9 & 14,9 & 10,6 & 23,4 & $\mathbf{1 0 0 , 0}$ \\
\hline \multicolumn{1}{|c|}{ Total } & $\mathbf{1 5 , 9}$ & $\mathbf{1 6 , 5}$ & $\mathbf{1 4 , 9}$ & $\mathbf{1 6 , 3}$ & $\mathbf{1 7 , 1}$ & $\mathbf{1 9 , 3}$ & $\mathbf{1 0 0 , 0}$ \\
\hline
\end{tabular}

Fonte: Pesquisa de campo (2011/2012)

A percepção quanto a esses pontos negativos variou nos diferentes terminais, o que parece estar vinculado à gestão de cada terminal, feita por diferentes empresas, chamando a atenção alguns pontos negativos que extrapolaram $20 \%$ do total de queixas, como é o caso da segurança, considerada precária, apontada nos terminais Maracaju (26,1\%), Marcos Freire $(23,4 \%)$, Zona Oeste $(23,3 \%)$ e Mercado $(21,8 \%)$. Também representando mais de $20 \%$ das queixas, está a falta de estrutura adequada para funcionamento e atendimento ao usuário no terminal de integração da Zona Sul, que representa $20,2 \%$ das queixas, e a falta de conforto no terminal Marcos Freire, representado $21,3 \%$ dos pontos negativos levantados. Apenas um aspecto se destaca por ser pouco apontado como problema, que é a higiene no terminal de integração do Campus Universitário, representando apenas 4,9\% das queixas.

0 ponto de vista dos pesquisados sobre as condições consideradas negativas nos terminais de integração parece não levar em consideração que parte dos pontos negativos observados por eles não se re- laciona exclusivamente a problemas de gestão, mas são provocados pelas atitudes dos próprios usuários desse espaço. Isso pode ser observado com relação à higiene/limpeza da área do terminal de integração, que foi apontada como deficiente, mas não houve qualquer menção ao fato de existirem várias lixeiras espalhadas por todo terminal que nem sempre são utilizadas pelos usuários desse local, os quais jogam o lixo no chão sem se preocupar em verificar a existência de lixeiras. É possível também observar que muitas lixeiras estão quebradas, aparentemente por atos de vandalismo dos próprios usuários. A questão da higiene e dos atos de vandalismo se repete dentro dos banheiros públicos, considerados bastante ruins.

Outro ponto negativo apontado pelos entrevistados e observado pelas pesquisadoras é a violência e desrespeito que ocorrem no momento da entrada e saída dos ônibus, levando crianças, velhos e demais usuários a sofrerem com empurrões, cotoveladas, arranhões, dentre outros agravos. Esse problema, que tem raízes culturais, também está relacionado à falta de infraestrutura e de organização dos gestores dos 
terminais de integração, que não adequam o espaço da área de embarque à formação de filas, nem mantêm fiscalização adequada para coibir a violência no momento do embarque e do desembarque.

Percebe-se que, quando o ônibus faz sua parada dentro do terminal, os passageiros que aguardam do lado de fora se aglomeram nas portas dos ônibus antes mesmo que elas se abram, impedindo, assim, a saída do passageiro que está dentro do ônibus, muitas vezes ocasionando confusão. Muitos forçam a entrada no transporte antes mesmo que o passageiro que está para descer do ônibus saia, ocasionando embates que por vezes causam ferimentos.

Tais transtornos são devidos ao fato de que, apesar de o ônibus ter três portas, dentro dos terminais funcionam apenas duas e a entrada e saída de pessoas por essas portas não são organizadas pelas empresas que coordenam os terminais, nem pelo órgão gestor, para ser uma de descida e outra de subida. Ambas, inicialmente, funcionam para descida e depois os passageiros que aguardam nos terminais sobem pelas mesmas portas.

\section{CONSIDERAÇÕES FINAIS}

O ambiente construído social e historicamente é fruto da interação contínua entre sociedade e um espaço físico particular que é continuamente modificado. Os terminais de integração, como ambientes construídos para a melhoria da mobilidade urbana dentro da cidade, também passam por modificações em seu espaço ao longo do tempo, devido ao uso cotidiano e às adaptações necessárias decorrentes de mudanças no sistema de transporte e do volume de passageiros atendidos.

Os terminais de integração devem ser substancialmente melhorados, com adequação dos espaços de embarque/desembarque para que possam ser estabelecidos e praticados comportamentos que respeitem
Outro fato observado, e de grande relevância, é a questão da entrada e saída do transporte, de pessoa com deficiência física. Os passageiros que estão à espera ou dentro do ônibus se irritam por não querer esperar o tempo necessário ao procedimento, e como muitos se aglomeram nas portas para entrada no transporte, as pessoas com deficiência física ficam à mercê de alguém para ajudá-las a entrar no ônibus.

A falta de fiscalização acarreta outro problema que é a superlotação dos ônibus, fator responsável por boa parte dos acidentes que ocorrem no uso do transporte coletivo em Aracaju.

Considerando essa série de pontos negativos apontados pelos usuários e o resultado da observação direta, é possível inferir que os terminais de integração, embora sejam bastante úteis e estratégicos na ligação entre as várias partes da cidade pelo preço de uma só tarifa, precisam ser bastante melhorados e a população precisa ser alvo de ações educativas eficazes, para melhor utilizar o sistema de transporte coletivo urbano de Aracaju e garantir melhor qualidade no atendimento dos usuários, com respeito aos seus direitos e às suas limitações.

os direitos dos cidadãos de acesso ao transporte coletivo com segurança e conforto, considerando-se as diferentes necessidades dos passageiros de ônibus, como deficientes físicos, idosos e crianças.

Concomitantemente a essas ações, é necessário o desenvolvimento de outras, visando a mudar o comportamento da população usuária dos terminais de integração para que entenda a coisa pública como responsabilidade de todos, que devem cuidar da sua melhoria e manutenção. Os comportamentos inadequados dos usuários devem orientar ações educativas acompanhadas de fiscalização efetiva, para promover o cuidado com o ambiente construído e o respeito e 
cuidado com o próximo. Essas ações devem ser planejadas e desenvolvidas pelos gestores de cada terminal de integração em parceria com a gestão municipal, acompanhada de veiculação de propaganda educativa massiva. A capacitação da população em geral para que usufrua das vantagens e bem estar proporcionado pelas políticas públicas é requisito fundamental para a melhoria das condições de vida da população e, portanto, a ação educativa deve, necessariamente, ser desenvolvida de forma permanente.

Essas ações educativas são ainda mais importantes porque boa parte da população estudantil do ensino público utiliza o transporte coletivo para o deslocamento diário entre residência e escola, ocasião em que enfrentam condições que são contrárias aos valores ensinados formalmente sobre direitos do cidadão, respeito ao próximo, solidariedade e outros.

\section{REFERÊNCIAS}

BRASIL. Constituição da República Federativa do Brasil de 1988. Disponível em:<www.planalto.gov.br>. Acesso em: 04 jan 2011

BRASIL. Lei n 10.257 de 10 de julho de 2001. Estatuto da Cidade. Regulamenta os arts. 182 e 183 da Constituição Federal, estabelece diretrizes gerais da política urbana e dá outras providências. Disponível em:<www. planalto.gov.br>. Acesso em: 04 jan 2011.

BRASIL. Lei n 12.587 de 03 de janeiro de 2012. Institui as diretrizes da Política Nacional de Mobilidade Urbana; revoga dispositivos dos Decretos-Leis nos 3.326, de 3 de junho de 1941, e 5.405, de 13 de abril de 1943, da Consolidação das Leis do Trabalho (CLT), aprovada pelo Decreto-Lei no 5.452, de 10 de maio de 1943, e das Leis nos 5.917, de 10 de setembro de 1973, e 6.261, de 14 de novembro de 1975; e dá outras providências. Disponível em: <www.planalto.gov.br>. Acesso em: 04 jan 2011
Todos esses aspectos relacionam-se com gestão do Estado e a maneira que o cidadão dispõe dos seus direitos, como o uso e manutenção do bem público, que é uma questão da falta de efetivação das políticas públicas. Neste caso, o prefeito é o gestor social, o ator político, condutor do desenvolvimento de políticas públicas adequadas às condições da cidade, sendo que todas as políticas públicas que afetam o município devem ter como preocupação central a capacidade de melhorar a qualidade de vida da população.

E, no caso dos transportes públicos por ônibus em Aracaju, outro fator deve ser considerado: a falta de licitação pública para concessão do direito de explorar o transporte urbano dificulta a ação do gestor, neste caso o município, no planejamento do sistema, estabelecimento de condições de operação e fiscalização da eficiência e qualidade dos serviços prestados.

GOMIDE, A. A. Transporte Urbano, Pobreza e Inclusão Social. XVII CONGRESSO DE PESQUISA EM ENSINO DE TRANSPORTE. Anais. Pp. 1082-1093. Natal/RN 2003. INSTITUTO BRASILEIRO DE GEOGRAFIA E ESTATÍSTICA - IBGE. Censo Demográfico 2010. Instituto Brasileiro de Geografia e Estatística. 2010.

KOIZUMI, Maria Sumie; JORGE, Maria Helena Prado de Mello. Acidentes de trânsito no Brasil: um atlas de sua distribuição. São Paulo: ABRAMET, 2007.

ROSA, S. J. Transporte e exclusão social: a mobilidade da população de baixa renda da Região Metropolitana de São Paulo e trem metropolitano. 2006. Dissertação(Mestrado em Engenharia). Escola Politécnica de São Paulo. Universidade de São Paulo. São Paulo, 2006. 
SAULE JR., Nelson. Estatuto da cidade e o plano diretor: possibilidades de uma nova ordem legal urbana justa e democrática. In: OSÓRIO, Letícia Marques. Estatuto da Cidade e reforma urbana: novas perspectivas para as cidades brasileiras. Porto Alegre: Sergio Antonio Fabris Editor, 2002. Ambiente da Unit. Graduada em Direito (2009) e em Serviço Social (1999) pela Universidade Tiradentes, especialista em Planejamento e Gestão de Projetos Sociais (2008) pela Unit. Membro do Grupo de Pesquisa Desenvolvimento Humano, Ambiente e Promoção da Saúde. e-mail: srpbraganca@hotmail.com

II Professora do curso de Serviço Social e do curso de Mestrado em Saúde e Ambiente da UNIT. Pesquisadora do ITP. Graduada em Ciências Sociais (1968) pela Faculdade de Filosofia, Ciências e Letras de Rio Claro, especialista em Dinâmica Populacional (1970) pela USP, mestre em Geografia/Organização do Espaço (1980) pela Unesp, doutora em Geografia/ Planejamento Regional pela Unesp (1988). Grupo de Pesquisa Desenvolvimento Humano, Ambiente e Promoção da Saúde. Instituto de Tecnologia e Pesquisa e Universidade Tiradentes. Aracaju/SE. E-mail: vania@ infonet.com.br 